\title{
Microbiologia de swabs retais e otológicos em carnívoros silvestres do zoológico do Parque Estadual de Dois Irmãos, Pernambuco ${ }^{1}$
}

\author{
Débora Costa Viegas de Lima², Daniel Barreto Siqueira ${ }^{3}$, Rinaldo Aparecido \\ Mota $^{4 *}$, Luciana Carla Rameh-de-Albuquerque ${ }^{3}$, Dênisson Silva Souza ${ }^{3}$, André \\ de Souza Santos ${ }^{4}$ e Leonildo Bento Galiza da Silva ${ }^{4}$
}

\begin{abstract}
Lima D.C.V., Siqueira D.B., Mota R.A., Rameh-de-Albuquerque L.C., Souza S.D., Santos A.S. \& Silva L.B.G. 2012. [Microbiology of rectal and otologic swabs of wild carnivores from the Zoo of the Parque Estadual de Dois Irmãos, Pernambuco, Brazil.] Microbiologia de swabs retais e otológicos em carnívoros silvestres do zoológico do Parque Estadual de Dois Irmãos, Pernambuco. Pesquisa Veterinária Brasileira 32(2):159-164. Laboratório de Doenças Infectocontagiosas, Departamento de Medicina Veterinária, Universidade Federal Rural de Pernambuco, Rua Dom Manuel de Medeiros s/n, Dois Irmãos, Recife, PE 52171-900, Brazil. E-mail: rinaldo.mota@hotmail.com

The epidemiological study of pathogens in wild populations in the environment in situ and ex situ is essential for implementation of prevention, control and monitoring of diseases and for development of public policies for public and animal health. The study was conducted at the Zoo of Parque Estadual de Dois Irmãos, Recife/PE, Brazil, from January to July 2011, where we collected anal and otological swabs from 29 Zoo's captive wild carnivores. The analysis of the otological swabs showed that 1/29 (3.4\%) were positive for Malassezia pachydermatis on direct examination. In the microbiological examination of otologic swabs we found mainly bacteriae of the genus Bacillus 16/29 (55.2\%), followed by Staphylococcus 15/29 (51.7\%), Escherichia coli 7/29 (24.1\%), Streptobacillus 1/29 (3.4\%), Micrococcus $1 / 29$ (3.4\%) and Klebsiella 1/29 (3.4\%). Regarding the presumptive test for the genus Salmonella from rectal swabs, positive samples were observed in six foxes (Cerdocyon thous) and a raccoon (Procyon cancrivorus). The isolation of Salmonella spp. in C. thous and P. cancrivorus indicates risks to public health, especially for zoo professionals who work directly with these animals. This research reinforces the importance of establishing surveillance strategies aimed at prevention, control and monitoring of potential reservoirs of the etiologic agents of infectious and parasitic diseases in the environment of zoos.
\end{abstract}

INDEX TERMS: Pathogens, wild carnivores, malassezia, Salmonella, public health.

RESUMO.- 0 estudo epidemiológico de patógenos em populações selvagens no ambiente in situ e ex situ é fundamental para implementação de programas de prevenção, controle e monitoramento de enfermidades e para elabo-

\footnotetext{
${ }^{1}$ Recebido em 14 de dezembro de 2011.

Aceito para publicação em 4 de janeiro de 2012.

${ }^{2}$ Departamento de Medicina Veterinária, Universidade Federal Rural de Pernambuco (UFRPE), Rua Dom Manuel de Medeiros s/n. Dois Irmãos. Recife, PE 52171-900, Brasil. E-mail: deblita_@hotmail.com

${ }^{3}$ Parque Estadual de Dois Irmãos (PEDI), Praça Farias Neves s/n, Dois Irmãos, Recife, PE 52171-011. E-mail: danielbsiqueira@yahoo.com.br

${ }^{4}$ Laboratório de Doenças Infectocontagiosas, Departamento de Medicina Veterinária, UFRPE, Rua Dom Manuel de Medeiros s/n, Dois Irmãos, Recife, PE 52171-900. *Autor para correspondência: rinaldo.mota@hotmail.com
}

ração de políticas públicas de saúde pública e animal. 0 estudo foi realizado no zoológico do Parque Estadual de Dois Irmãos no período de janeiro a julho de 2011 onde foram coletados swabs anais e otológicos referentes a 29 carnívoros silvestres cativos do zoológico. Dos swabs otológicos analisados, $1 / 29(3,4 \%)$ foi positivo para Malassezia pachydermatis no exame direto. No exame microbiológico dos swabs otológicos, observou-se maior freqüência para bactérias do gênero Bacillus 16/29 (55,2\%), seguida de Staphylococcus 15/29 (51,7\%), Escherichia coli $7 / 29(24,1 \%)$, Streptobacillus 1/29 (3,4\%), Micrococcus 1/29 (3,4\%) e Klebsiella 1/29 (3,4\%). Com relação ao exame presuntivo para o gênero Salmonella a partir das amostras de swab retal, observou-se positividade para seis raposas (Cerdocyon 
thous) e um guaxinim (Procyon cancrivorus). 0 isolamento de Salmonella spp. em C. thous e em P. cancrivorus indica um risco à saúde pública, principalmente para os profissionais do zoológico que trabalham diretamente com esses animais. Essa pesquisa reforça a importância da criação de estratégias de vigilância epidemiológica voltadas para a prevenção, controle e monitoramento de potenciais reservatórios de agentes etiológicos de doenças infecciosas e parasitárias no ambiente dos zoológicos.

TERMOS DE INDEXAÇÃO: Patógenos, carnívoros silvestres, $m a-$ lassezia, Salmonella, saúde pública.

\section{INTRODUÇÃO}

O estudo epidemiológico de patógenos em populações selvagens no ambiente in situ e ex situ é fundamental para implementação de programas de prevenção, controle e monitoramento de enfermidades e para elaboração de políticas públicas de saúde pública e animal (Jorge et al. 2010).

Salmonella spp. são bactérias Gram-negativas, móveis, que podem infectar a maioria das espécies de animais, entre mamíferos, aves e répteis, inclusive os humanos, sendo considerada uma zoonose de grande importância fecal-oral, ocorrendo principalmente pelo contato direto ou indireto com animais infectados ou pela ingestão de alimentos ou água contaminada (Carvalho 2006).

A otite é uma enfermidade multifatorial resultante do processo inflamatório da cavidade auditiva tendo origem na região externa e podendo prolongar-se até o sistema vestíbulo-coclear. Esse processo migratório geralmente é acompanhado por complicações mais graves e extensas (Greene 1993). Malassezia pachydermatis é uma levedura de natureza oportunista, tornando-se patogênica quando há uma alteração no ambiente microbiológico da superfície da pele ou no sistema imunológico do hospedeiro levando a um quadro de otite (Mendes et al. 2011). Outras espécies que também podem provocar otite são Malassezia globosa e M. sympodialis (Coutinho et al. 2006).

Objetivou-se com este trabalho realizar um estudo sobre a ocorrência de Salmonella spp., Malassezia sp. e outros patógenos em swabs retais e otológicos de carnívoros silvestres cativos no zoológico do Parque Estadual de Dois Irmãos, Recife, Pernambuco.

\section{MATERIAL E MÉTODOS}

0 estudo foi realizado no zoológico do Parque Estadual de Dois Irmãos (Latitude: $8^{\circ} 0^{\prime} 20.79^{\prime \prime}$, Longitude: 3456'51.85”0), uma Unidade de Conservação de 384,42 hectares localizado no município de Recife, Pernambuco, e considerada uma das mais importantes reservas de Mata Atlântica do Nordeste do Brasil.

No período de janeiro a julho de 2011 foram anestesiados 29 carnívoros silvestres cativos, sendo 1 Panthera onca (onça-pintada), 1 Panthera tigris altaica (tigre-siberiano), 1 Puma yagouaroundi (gato-mourisco), 1 Leopardus pardalis (jaguatirica), 1 Leopardus tigrinus (gato-do-mato-pequeno), 9 Cerdocyon thous (raposa), 2 Eira barbara (irara), 1 Galictis cuja (furão), 2 Procyon cancrivorus (guaxinim) e 10 Nasua nasua (quati).

A contenção física dos pequenos carnívoros foi realizada com o auxílio de um puçá. 0 protocolo anestésico foi realizado com a associação do cloridrato de cetamina $(10 \mathrm{mg} / \mathrm{kg} / \mathrm{IM}$, exceto:
$12 \mathrm{mg} / \mathrm{kg} / \mathrm{IM}$, jaguatirica) com o cloridrato de xilazina $(1 \mathrm{mg} / \mathrm{kg} /$ IM). Os grandes felinos ( $P$. onca e $P$. tigris altaica) foram anestesiados utilizando-se uma zarabatana e dardos anestésicos. Para P. onca os fármacos foram combinados numa preparação concentrada denominada "ZAD", sendo tiletamina e zolazepan desidratados de um frasco do produto Zoletil $/ 100 ®+0,50 \mathrm{~mL}$ de sulfato de atropina $1 \%+0,53 \mathrm{~mL}$ de cloridrato de detomidina (Dormiun- $\mathrm{B} ®$ $1 \%)+1,30 \mathrm{~mL}$ de água destilada (Pachally \& Voltarelli-Pachally 2011), sendo administrados 1,3mL do "ZAD". Para P. tigris altaica o protocolo anestésico foi calculado por extrapolação alométrica (Pachally et al. 2011) sendo realizado com a associação de $0,52 \mathrm{~mL}$ de Dormiun-V® $1 \%(0,02 \mathrm{mg} / \mathrm{kg})+0,49 \mathrm{~mL}$ de sulfato de atropina $1 \%(0,02 \mathrm{mg} / \mathrm{kg})+8,0 \mathrm{~mL}$ de cloridrato de cetamina $\mathrm{S}(+) \circledast 5 \%$ $(1,9 \mathrm{mg} / \mathrm{kg})$.

A colheita das amostras biológicas foi realizada por meio de swab retal e otológico (Fig.1), sendo imediatamente encaminhada sob refrigeração em um cooler portátil contendo gelo para processamento no Laboratório de Doenças Infecto-Contagiosas da Universidade Federal Rural de Pernambuco.

Uma alíquota das amostras de swab otológico foi semeada em ágar sangue de ovino. As placas foram incubadas em estufa bacteriológica a uma temperatura de $37^{\circ} \mathrm{C}$ por $24 \mathrm{~h} \mathrm{e}$, em seguida, foram avaliadas as características morfológicas das colônias isoladas e procedeu-se a técnica de Gram. Para a identificação das bactérias isoladas foram utilizados testes bioquímicos em meios TSI, Citrato, SIM, Lisina, VM, VP e uréia.

Outra alíquota das amostras de swab otológico foi fixada em lâmina de microscopia em chama e corada pela técnica de Gram, sendo em seguida realizado o exame direto em microscopia óptica para pesquisa de Malassezia sp.

Para o isolamento de Salmonella spp., uma alíquota das amostras de $s w a b$ anal foi primeiramente submetida ao processo de pré-enriquecimento (Água Peptonada) e enriquecimento seletivo (Caldos Rappaport e Tetrathionato). Posteriormente as amostras foram semeadas em meios semi-sólidos (ágar XLD e Verde Brilhante), onde foi possível visualizar o crescimento de colônias características sugestivas deste gênero que, posteriormente, foram analisadas por testes bioquímicos de acordo com Litchfield (1973).

\section{RESULTADOS}

Os animais apresentavam-se clinicamente sadios e com boa condição corporal, com exceção de três indivíduos, sendo um Leopardus tigrinus que apresentava várias lesões por

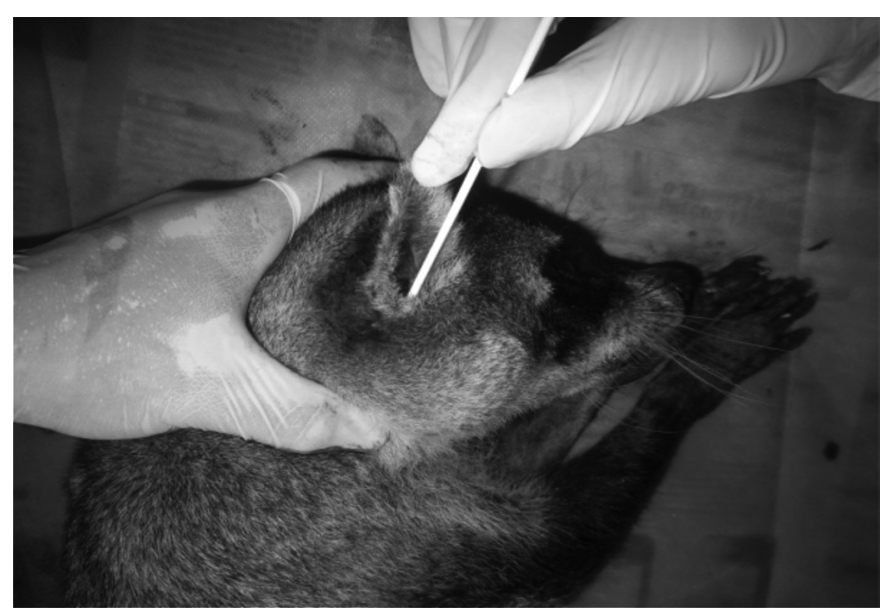

Fig.1. Colheita de swab otológico realizado no ouvido direito de um guaxinim (Procyon cancrivorus). 
mordeduras ocasionadas por brigas com outro indivíduo da mesma espécie e dois $P$. cancrivorus, onde um apresentava rarefação pilosa na face lateral do membro posterior direito e ao longo da cauda e o outro com rarefação pilosa na região proximal do membro anterior direito.

Dos swabs otológicos analisados, $1 / 29(3,4 \%)$ foi positivo para Malassezia pachydermatis no exame direto. No exame microbiológico dos swabs otológicos foram observados diferentes microrganismos (Quadro 1).

Desses microrganismos, observou-se maior freqüência para bactérias do gênero Bacillus 16/29 (55,2\%), seguida de Staphylococcus 15/29 (51,7\%), Escherichia coli 7/29 $(24,1 \%)$, Streptobacillus $1 / 29$ (3,4\%), Micrococcus $1 / 29$ $(3,4 \%)$ e Klebsiella $1 / 29$ (3,4\%).

Com relação ao exame presuntivo para o gênero Salmonella a partir das amostras de swab retal (Quadro 2), observou-se positividade para seis raposas (C. thous) e um guaxinim (P. cancrivorus).

\section{DISCUSSÃO}

Malassezia pachydermatis é uma levedura que faz parte da microbiota dos condutos auditivos de animais sadios (Avila et al. 2004) e também é considerado o principal microrganismo que contribui para a perpetuação das otites (Scott et al. 1995). É um fungo oportunista que se torna patogênico em situações de imunossupressão e estresse podendo causar infecções superficiais ou profundas, ou ainda reações de hipersensibilidade (Mendes et al. 2011). 0 aumento da umidade, temperatura e o substrato podem determinar uma elevação no número de leveduras, ocorrendo transição da sua forma comensal para o parasitismo (Avila et al. 2004).

Quadro 1. Microbiologia de swabs otológicos em carnívoros silvestres do zoológico do Parque Estadual de Dois Irmãos, Pernambuco

\begin{tabular}{|c|c|c|c|c|c|}
\hline Espécie & Sexo & Idade & Identificação & Resultado & Frequência (\%) \\
\hline Cerdocyon thous & Macho & Adulto & 963008000020759 * & $\begin{array}{l}\text { Bacillus sp. } \\
\text { Staphylococcus sp }\end{array}$ & $\begin{array}{l}16 / 42(38,1) \\
15 / 42(11,9)\end{array}$ \\
\hline Cerdocyon thous & Fêmea & Jovem & 963008000019707 * & Bacillus sp. & $16 / 42(38,1)$ \\
\hline Cerdocyon thous & Fêmea & Jovem & $963008000021522 *$ & Bacillus sp. & $16 / 42(38,1)$ \\
\hline Cerdocyon thous & Fêmea & Jovem & $963007000055019 *$ & Bacillus sp. & $16 / 42(38,1)$ \\
\hline Cerdocyon thous & Fêmea & Jovem & 963007000055560 * & Klebsiella sp. & $1 / 42(2,4)$ \\
\hline Cerdocyon thous & Fêmea & Adulta & 963008000019587 * & $\begin{array}{l}\text { Escherichia coli } \\
\text { Bacillus sp. }\end{array}$ & $\begin{array}{c}7 / 42(16,7) \\
16 / 42(38,1)\end{array}$ \\
\hline Cerdocyon thous & Fêmea & Jovem & 963008000021511 * & Escherichia coli & $7 / 42(16,7)$ \\
\hline Cerdocyon thous & Macho & Jovem & $963007000057866 *$ & Staphylococcus sp. & $15 / 42(11,9)$ \\
\hline Cerdocyon thous & Macho & Idoso & 963008000021193 * & $\begin{array}{l}\text { Bacillus sp. } \\
\text { Malassezia pachydermatis }\end{array}$ & $\begin{array}{c}16 / 42(38,1) \\
1 / 42(2,4)\end{array}$ \\
\hline Galictis cuja & Macho & Adulto & 963008000020574 * & Staphylococcus sp. & $15 / 42(11,9)$ \\
\hline Eira Barbara & Macho & Adulto & PEDI $001 * *$ & Flora contaminante & --- \\
\hline Eira Barbara & Fêmea & Adulta & $963008000020752 *$ & Bacillus sp. & $16 / 42(38,1)$ \\
\hline Leopardus pardalis & Macho & Adulto & 963008000030700 * & $\begin{array}{l}\text { Bacillus sp. } \\
\text { Staphylococcus sp. } \\
\text { Staphylococcus sp. }\end{array}$ & $\begin{array}{l}16 / 42(38,1) \\
15 / 42(11,9) \\
15 / 42(11,9)\end{array}$ \\
\hline Nasua nasua & Macho & Adulto & $963008000021415^{*}$ & Bacillus sp. & $16 / 42(38,1)$ \\
\hline Nasua nasua & Macho & Adulto & $963008000019711 *$ & $\begin{array}{l}\text { Staphylococcus sp. } \\
\text { Bacillus sp. }\end{array}$ & $\begin{array}{l}15 / 42(11,9) \\
16 / 42(38,1)\end{array}$ \\
\hline Nasua nasua & Fêmea & Adulta & 963008000020740 * & $\begin{array}{l}\text { Bacillus sp. } \\
\text { Micrococcus sp. }\end{array}$ & $\begin{array}{c}16 / 42(38,1) \\
1 / 42(2,4)\end{array}$ \\
\hline Nasua nasua & Fêmea & Adulta & 963008000021070 * & $\begin{array}{l}\text { Staphylococcus sp. } \\
\text { Escherichia coli }\end{array}$ & $\begin{array}{c}15 / 42(11,9) \\
7 / 42(16,7)\end{array}$ \\
\hline Nasua nasua & Fêmea & Adulta & Sem marcação & $\begin{array}{l}\text { Bacillus sp. } \\
\text { Staphylococcus sp. }\end{array}$ & $\begin{array}{l}16 / 42(38,1) \\
15 / 42(11,9)\end{array}$ \\
\hline Nasua паsua & Fêmea & Adulta & 963007000084351 * & $\begin{array}{l}\text { Bacillus sp. } \\
\text { Eschericihia coli }\end{array}$ & $\begin{array}{c}16 / 42(38,1) \\
7 / 42(16,7)\end{array}$ \\
\hline Nasua паsua & Fêmea & Adulta & 963008000021454 * & $\begin{array}{l}\text { Staphylococcus sp. } \\
\text { Streptobacillus }\end{array}$ & $\begin{array}{c}15 / 42(11,9) \\
1 / 42(2,4)\end{array}$ \\
\hline Nasua nasua & Fêmea & Adulta & 963008000019751 * & $\begin{array}{l}\text { Bacillus sp. } \\
\text { Escherichia coli }\end{array}$ & $\begin{array}{c}16 / 42(38,1) \\
7 / 42(16,7)\end{array}$ \\
\hline Nasua nasua & Fêmea & Adulta & 963008000030680 * & Escherichia coli & $7 / 42(16,7)$ \\
\hline Nasua nasua & Macho & Filhote & Sem marcação & $\begin{array}{l}\text { Staphylococcus sp. } \\
\text { Bacillus sp }\end{array}$ & $\begin{array}{l}15 / 42(11,9) \\
16 / 42(38,1)\end{array}$ \\
\hline Panthera tigris altaica & Fêmea & Adulta & 963000000151351 * & Staphylococcus sp. & $15 / 42(11,9)$ \\
\hline Procyon cancrivorus & Fêmea & Adulta & 963008000021573 * & Staphylococcus sp. & $15 / 42(11,9)$ \\
\hline Procyon cancrivorus & Fêmea & Adulta & $963008000021292 *$ & $\begin{array}{l}\text { Staphylococcus sp. } \\
\text { Bacillus sp. }\end{array}$ & $\begin{array}{l}15 / 42(11,9) \\
16 / 42(38,1)\end{array}$ \\
\hline Puma yagouaroundi & Fêmea & Adulta & 963008000020593 * & $\begin{array}{l}\text { Escherichia coli } \\
\text { Staphylococcus sp. }\end{array}$ & $\begin{array}{c}7 / 42(16,7) \\
15 / 42(11,9)\end{array}$ \\
\hline
\end{tabular}


Quadro 2. Isolamento de Salmonella spp em carnívoros silvestres cativos no zoológico do Parque Estadual de Dois Irmãos, Pernambuco

\begin{tabular}{|c|c|c|c|c|}
\hline Espécie & Sexo & Idade & Identificação & Resultado \\
\hline Panthera onca & Fêmea & Adulta & $190991^{*}$ & Negativo \\
\hline Panthera tigris altaica & Fêmea & Adulta & $963000000151351 *$ & Negativo \\
\hline Puma yagouaroundi & Fêmea & Adulta & $963008000020593 *$ & Negativo \\
\hline Leopardus pardalis & Macho & Adulto & PEDI $020^{* *}$ & Negativo \\
\hline Leopardus tigrinus & Fêmea & Idosa & $963008000030700 *$ & Negativo \\
\hline Cerdocyon thous & Macho & Adulto & $963008000020759 *$ & Negativo \\
\hline Cerdocyon thous & Fêmea & Jovem & $963008000019707 *$ & Positivo \\
\hline Cerdocyon thous & Fêmea & Jovem & $963008000021522 *$ & Positivo \\
\hline Cerdocyon thous & Fêmea & Jovem & $963007000055019 *$ & Positivo \\
\hline Cerdocyon thous & Fêmea & Jovem & $963007000055560 *$ & Positivo \\
\hline Cerdocyon thous & Fêmea & Adulta & $963008000019587 *$ & Positivo \\
\hline Cerdocyon thous & Fêmea & Jovem & $963008000021511 *$ & Positivo \\
\hline Cerdocyon thous & Macho & Jovem & $963007000057866^{*}$ & Negativo \\
\hline Cerdocyon thous & Macho & Idoso & $963008000021193 *$ & Negativo \\
\hline Eira Barbara & Macho & Adulto & PEDI $001^{* *}$ & Negativo \\
\hline Eira Barbara & Fêmea & Adulta & $963008000020752 *$ & Negativo \\
\hline Galictis cuja & Macho & Adulto & $963008000020574 *$ & Negativo \\
\hline Procyon cancrivorus & Fêmea & Adulta & $963008000021573^{*}$ & Positivo \\
\hline Procyon cancrivorus & Fêmea & Adulta & $963008000021292 *$ & Negativo \\
\hline Nasua nasua & Macho & Adulto & $963008000021415 *$ & Negativo \\
\hline Nasua nasua & Macho & Adulto & $963008000019711 *$ & Negativo \\
\hline Nasua nasua & Fêmea & Adulta & $963008000020740 *$ & Negativo \\
\hline Nasua nasua & Fêmea & Adulta & $963008000021070 *$ & Negativo \\
\hline Nasua nasua & Fêmea & Adulta & Sem marcação & Negativo \\
\hline Nasua nasua & Fêmea & Adulta & $963007000084351 *$ & Negativo \\
\hline Nasua nasua & Fêmea & Adulta & $963008000021454 *$ & Negativo \\
\hline Nasua nasua & Fêmea & Adulta & $963008000019751 *$ & Negativo \\
\hline Nasua nasua & Fêmea & Adulta & $963008000030680 *$ & Negativo \\
\hline Nasua nasua & Macho & Filhote & Sem marcação & Negativo \\
\hline
\end{tabular}

Das 29 amostras de carnívoros silvestres analisadas nesta pesquisa, uma $(3,4 \%)$ apresentou-se positiva para Malassezia pachydermatis, essa referente a uma raposa $(C$. thous). Em outros estudos realizados com carnívoros clinicamente sadios mantidos em cativeiro no Brasil, Coutinho et al. (2006) isolou Malassezia sp. no conduto auditivo de felídeos silvestres 58/132 (43,9\%) no estado de São Paulo, e Bentubo et al. (2006a) de gatos-do-mato-pequeno (Leopardus tigrinus) 21/38 (55,3\%) oriundos da Fundação Parque Zoológico de São Paulo.

Outros estudos realizados no Brasil também relataram a presença de $M$. pachydermatis no conduto auditivo de animais clinicamente saudáveis como macacos-prego ( $\mathrm{Ce}$ bus apella) 6/27 (22,22\%), bugios (Alouatta caraya) 3/16 $(18,75 \%)$, sagui (Callithrix sp.) $1 / 12(8,33 \%)$, tamanduás-mirim (Tamanduá tetradactyla) 3/13 (11,1\%) (Avila et al. 2004, Bentubo et al. 2006b). Mendes et al. (2011) relataram a presença de $M$. pachydermatis no cerume, que se apresentava de coloração escurecida, e em pêlos colhidos de lesões provenientes da região abdominal de gambá-de-orelha-branca (Didelphis albiventris).

Sobre os outros microrganismos identificados nesta pesquisa observou-se que E. coli estava presente no conduto auditivo clinicamente sadio de P. yagouaroundi 1/1 (100\%), Cerdocyon thous 2/9 (22,2\%) e Nasua nasua 4/10 (40\%). Essa bactéria faz parte da flora intestinal dos animais, podendo esses achados terem sido atribuídos à contaminação do ambiente em função do cativeiro proporcionar um maior contato dos animais com as suas excretas (Olinda et al. 2010).

As bactérias do gênero Bacillus apresentaram comportamento tipicamente saprofítico no microambiente auricu- lar de animais domésticos (Avila et al. 2008). Em carnívoros silvestres a presença desse microrganismo também parece ter o mesmo comportamento, pois foi isolado em 16/29 $(55,2 \%)$ dos animais estudados e todos apresentaram os condutos auditivos sem alteração clínica. No entanto, outros estudos indicaram Bacillus sp. apresentando capacidade de causar doença quando houve colonização intensa no epitélio da orelha de cães, resultando em um quadro clínico compatível com otite (Leite 1995, Leite 2003, Oliveira et al. 2006).

Staphylococcus sp. foi isolado no conduto auditivo de $15 / 29(51,7 \%)$ dos animais analisados, sendo encontrado em todas as espécies pesquisadas com exceção de E. barbara. Esta bactéria é frequentemente isolada de diferentes espécies de animais selvagens e domésticos e é uma das bactérias mais importantes para a medicina veterinária devido a sua associação com várias enfermidades e sua alta resistência a antibióticos (Mangini et al. 2002, Vintov et al. 2003, May et al. 2005, Verona \& Pissinatti 2006).

As bactérias menos frequentes neste trabalho foram Klebsiella sp., Micrococcus sp. e Streptobacillus sp. Avila et al. (2008) isolaram diversos microrganismos associados à otite externa em cães domésticos, entre eles Staphylococcus intermedius (12,8\%), S. aureus (11\%), S. epidermidis (11\%), Klebsiella pneumoniae (5,5\%), S. saprophyticus (1,8\%) e Bacillus spp. (1,8\%). Segundo Quinn et al. (1999), S. epidermidis, S. intermedius, Micrococcus sp. e enterobactérias são geralmente encontradas nos ouvidos de cães clinicamente sadios.

O isolamento de Salmonella spp. em Cerdocyon thous e em Procyo cancrivorus indica risco à saúde pública, principalmente para os profissionais do zoológico que trabalham diretamente com esses animais. Por isso, medidas preventivas devem ser tomadas como lavagem, acondicionamento e manipulação adequada dos alimentos, desinfecção diária no setor de nutrição, remoção e eliminação dos restos de comida e fezes seguidas pela desinfecção adequada dos recintos, utilização de equipamentos de proteção individual (EPI's) pelos funcionários, entre outros (Silva \& Corrêa 2006).

As raposas e o guaxinim são onívoros e sua dieta no cativeiro é composta por frutas, ovos cozidos, carne (bovina, frango e vísceras), ração peletizada e presa inteira (pinto, camundongo ou rato). Esses alimentos e a água podem servir de fontes de infecção por Salmonella spp. (Gilioli \& Silva 2000). Outras importantes fontes de infecção para os animais cativos são os roedores sinantrópicos, as aves e os répteis silvestres que têm acesso aos recintos (Davis \& Wray 1997, Gilioli \& Silva 2000). Entre os répteis, a lagartixa (Tropidurus hispidus) é bastante abundante no zoológico do Parque Estadual de Dois Irmãos. A confirmação da espécie de Salmonella spp. é importante para identificar quais sorotipos estão presentes no ambiente e para verificar o grau de patogenicidade, no entanto, não foi possível realizar a sorotipagem nesta pesquisa.

Em um estudo realizado por Millán et al. (2004) na Espanha, também foram isoladas de Salmonella spp. em 9/123 (7,3\%) de várias espécies de mamíferos silvestres, entre elas a raposa-vermelha (Vulpes vulpes) 1/14 (7,14\%), 
os texugos-europeus (Meles meles) 4/22 (18,18\%), os javalis (Sus scrofa) 3/40 $(7,5 \%)$ e a gineta-européia (Genetta genetta) 1/4 (2,5\%). Euden (1990) isolou 26 sorotipos diferentes de Salmonella spp. em texugos-europeus (Meles meles) de vida livre. Sorensen et al. (2005) isolou Salmonella spp. em 1/3 $(33,3 \%)$ raposa-selvagem-do-Ártico (Alopex lagopus). Nos EUA, Clyde et al. (1997) também isoloram a Salmonella thyphimurium em felinos exóticos.

No Brasil, Gilioli \& Silva (2000) isolaram quatro diferentes sorotipos de Salmonella em amostras de fezes de 6/24 lobos-guará (Chrysocyon brachyurus) mantidos em 11 zoológicos no estado de São Paulo, sendo os sorotipos encontrados o hadar, entereditis, senftenberg, enterica subsp. enterica. Dos animais positivos para o gênero, um apresentou sinais clínicos de salmonelose. Esses autores sugerem que os lobos-guarás apresentam alguma adaptação fisiológica a Salmonella spp. no trato gastrointestinal e que esses microrganismos podem ser mantidos como um componente da flora normal em animais imunocompetentes.

Embora a infecção por Salmonella spp. em mamíferos seja observada quadros de diarréia, anorexia, perda de peso e letargia, podendo evoluir para um quadro toxicêmico e até a morte (Fornazari \& Teixeira 2009), em nenhuma das raposas e guaxinim positivos para o gênero foram observados sinais clínicos compatíveis com salmonelose, podendo essas espécies também apresentar a mesma adaptação fisiológica à bactéria como observado nos lobos-guarás (Gilioli \& Silva 2000). Clyde et al. (1997) descreve que a capacidade de abrigar bactérias como a Salmonella com um comportamento não patogênico pode ser uma adaptação em carnívoros.

Os resultados desta pesquisa demonstraram que os microorganismos de caráter patogênico isolados nos animais selvagens apresentaram um comportamento saprófito, tornando esta uma importante informação para os profissionais que trabalham com animais de zoológico, já que são patógenos que podem infectar outras espécies de animais, inclusive os humanos. Essa pesquisa também reforça a importância da criação de estratégias de vigilância epidemiológica voltadas para a prevenção, controle e monitoramento de potenciais reservatórios de agentes etiológicos de doenças infecciosas e parasitárias no ambiente dos zoológicos.

Agradecimentos.- À equipe do Laboratório de Doenças Infectocontagiosas (DMV/UFRPE). Aos tratadores do Parque Estadual de Dois Irmãos.

\section{REFERÊNCIAS}

Avila M.O., Fernandes C.G.N., Ribas J.A.S. \& Camargo L.M. 2004. Estudo da microbiota fúngica da pele, pelos e conduto auditivo de macacos clinicamente saudáveis, provenientes do reservatório de manso, MT, Brasil. Arqs Inst. Biológico, São Paulo, 71(1):27-30.

Avila M.O., Benetti A.H., Camargo L.M., Silva J. \& Nocciti D.P. 2008. Levantamento de bactérias presentes no conduto auditivo externo de cães com sintomatologia clínica de otite, atendidos no hospital veterinário da universidade de Cuiabá, estado de Mato Grosso, no período de fevereiro de 2003 a dezembro de 2007. Anais 35 Congresso Brasileiro de Medicina Veterinária, Gramado, RS.

Bentubo H.D.L., Filoni C., Catão-Dias J.L., Oliveira T.G. \& Coutinho S.D. 2006a. Avaliação micológica do tegumento de gatos-do-mato-pequenos (Leopardus tigrinus) de cativeiro e um grupo selecionado para reintrodução. Anais X Congresso e XV Encontro da Associação Brasileira de Veterinários de Animais Selvagens, p.63. (Resumo)
Bentubo H.D.L., Miranda F. \& Coutinho S.D. 2006b. Pesquisa de espécies de Malassezia e dermatófitos em pelame de tamanduás. Anais X Congresso e XV Encontro da Associação Brasileira de Veterinários de Animais Selvagens, p.68. (Resumo)

Carvalho V.M. 2006. Colibacilose e salmonelose, p.742-750. In: Cubas Z.S., Silva J.C. \& Catão-Dias J.L. (Eds), Tratado de Animais Selvagens. Roca, São Paulo.

Clyde V.L., Ramsay E.C. \& Bemis D.A. 1997. Fecal shedding of Salmonella in exotic felids. J. Zoo Wildl. Med. 28(2):148-152,

Coutinho S.D., Fedullo J.D. \& Correa S.H. 2006. Isolation of Malassezia spp. from cerumen of wild felids. Medical Mycol., Oxford, 44(4):383-387.

Davis R.H. \& Wray C. 1997. Distribution of Salmonella contamination in ten animal feedmills. Vet. Microbiol. 51:159-169.

Euden P.R. 1990. Salmonella isolates from wild animals in Cornwall. Brit. Vet. J. 146(3):228-32,

Fornazari F. \& Teixeira C.R. 2009. Salmonelose em répteis: Aspectos epidemiológicos, clínicos e zoonóticos. Vet. Zootec. 16:19-25.

Gilioli R. \& Silva F.A. 2000. Frequency of parasites and Salmonella infection in captive maned-wolf, Chrysocyon brachyurus, kept in Zoos at the State of São Paulo, Brazil. Arq. Bras. Med. Vet. Zootec. 52(4):337-341.

Greene C.E. 1993. Enfermidades Infecciosas: perros y gatos. Editora Interamericana.

Jorge R.S.P., Rocha F.L., Junior J.A.M. \& Morato R.G. 2010. Ocorrência de patógenos em carnívoros selvagens brasileiros e suas implicações para a conservação e saúde pública. Oecologia Australis 14(3):686-710.

Leite C.A.L. 1995. Isolamento, identificação e sensibilidade de agentes microbianos causadores de otite em cães (Canis familiaris). Dissertação de Mestrado, Escola de Veterinária, Universidade Federal de Minas Gerais, Belo Horizonte. 60p.

Leite C.A.L. 2003. Caracterização clínica e laboratorial de caninos hígidos e otopatas, com ênfase nas microbiotas aeróbica e anaeróbica dos condutos auditivos. Tese de Doutorado, Faculdade de Medicina Veterinária e Zootecnia, Universidade Estadual Paulista, Botucatu, SP. 237p.

Litchfield J.H. 1973. Salmonella and the food industry: methods for isolation, identification and enumeration. Critical Rev. Food Technol. 3:415-456.

Mangini P.R., Moraes, W. \& Santos, L.C. 2002. Enfermidades observadas em Tapirus terrestris (anta-brasileira) mantidas em cativeiro em Foz do Iguaçu, Paraná. Arqs Ciênc. Vet. Zool. Unipar 5:93-102.

May E.R., Hnilica K.A., Frank L.A., Jones R.D. \& Bemis D.A. 2005. Isolation of Staphylococcus schleiferi from healthy dogs and dogs with otitis, pyoderma, or both. Journal of the Am. Vet. Med. Assoc. 227(6):928-931.

Mendes J. F., Albano A.P.N., Santin R., Meireles M.C.A., Coimbra M.A.A., Leite A.T.M., Minello L.F. \& Nascente P.S. 2011. Ocorrência de Malassezia pachydermatis em gambá-de-orelha-branca (Didelphis albiventris). Revta Clín. Vet. 16(91):108-111.

Millán J., Aduriz G., Moreno B., Juste RA. \& Barral M. 2004. Salmonella isolates from wild birds and mammals in the Basque Country (Spain). Revue Scientifique et Technique 23(3):905-911.

Olinda R.B., Feijo F.M.C., Alvez N.D., Amorim R.N.L., Alves H.M., Batista J.S. \& Oliveira M.F. 2010. Otite bacteriana em cateto (Tayassu tajacu Linnaeus, 1758) criado em cativeiro. Acta Veterinaria Brasilica 4(2):113-117.

Oliveira L.C., Brilhante R.S.N., Cunha A.M.S. \& Carvalho C.B.M. 2006. Perfil de isolamento microbiano em cães com otite média e externa associadas. Arq. Bras. Med. Vet. Zootec. 58(6):1009-1017.

Pachally J.R. \& Voltarelli-Pachally E.M. 2011. Novo método para contenção farmacológica e anestesia de campo em leões (Panthera leo), empregando a fórmula "ZAD" (Zoletil/100® + atropina + Dormiun-V®): relato preliminar. Hora Vet. 31(181):75-80.

Pachally J.R., Alberton L.R., Voltarelli-Pachally E.M., Belettini S.T., Monteiro-Filho L.P.C. \& Carneiro R.C. 2011. Doses alométricas de cloridrato de detomidina para uso na contenção farmacológica de mamíferos selvagens placentários não xenartros, isoladamente ou em associação a outros fármacos sedativos ou anestésicos. MedVep, Revta Cient. Med. Vet., Peq. Anim. e Anim. Estimação 9(30):462-469.

Quinn P.J., Carter M.E., Markey B. \& Carter G.R. 1999. Clinical Veterinary Microbiology. Mosby, Londres. 648p. 
Scott D.W., Miller W.H. \& Griffin C.E. 1995. Doenças parasitárias da pele, p.392-468. In: Scott D.W., Miller W.H. \& Griffin C.E. (Eds), Muller e Kirk's Dermatologia de Pequenos Animais. $5^{\text {th }}$ ed. W.B. Saunders, Philadelphia.

Silva J.C.R. \& Corrêa S.H.R. 2006. Manejo sanitário e biosseguridade, p.1226-1244. In: Cubas Z.S., Silva J.C.R. \& Catão-Dias J.L. (Eds),Tratado de Animais Selvagens: medicina veterinária. Roca Press, São Paulo.

Sorensen K.K., Mork T., Sigurdardóttir O.G., Asbakk K., Akerstedt J., Bergsjo B. \& Fuglei E. 2005. Acute toxoplasmosis in three wild arctic foxes (Alopex lagopus) from Svalbard; one with co-infections of Salmonella en- teritidis PT1 and Yersinia pseudotuberculosis serotype 2b. Res. Vet. Sci. 78(2):161-167.

Verona C.E.S. \& Pissinatti A. 2006. Primatas: Primatas do novo mundo (sagui, macaco-prego, macaco-aranha, bugio), p.358-377. In: CubaS Z.S., Silva J.C.R. \& Catão-Dias J.L. (Eds), Tratado de Animais Selvagens: medicina veterinária. Roca Press, São Paulo.

Vintov J., Aarestrup F.M., Zinn C.E. \& Olsen J.E. 2003. Association between phage types and antimicrobial resistance among bovine Staphylococcus aureus from 10 countries. Vet. Microbiol. 95:133-147. 